\title{
Flavimonas oryzihabitans bacteremia and concomitant pleural tuberculosis
}

\author{
Ana Pando-Sandoval ${ }^{1}$, Miguel Ariza-Prota ${ }^{1}$, Marta Garcia-Clemente ${ }^{1}$, Herminia Buchelli- \\ Ramirez $^{1}$, Claudia Madrid ${ }^{1}$, Aleida Martínez-Zapico², Pere Casan ${ }^{1}$ \\ 1. Lung Clinical Area, Neumology, Hospital Universitario Central de Asturias, Oviedo, Asturias, Spain. 2. Internal Medicine \\ Clinical Area, Hospital Universitario Central de Asturias, Oviedo, Asturias, Spain.
}

Correspondence: Ana Pando-Sandoval. Address: Doctor Bellmunt s/n. Hospital Universitario Central de Asturias, Área de Gestión Clínica del Pulmón, Neumología, 33006, Oviedo, Asturias, Spain. Email: ana_pando@hotmail.com

Received: August 10, 2014

DOI : $10.5430 /$ crim.v2n1p30
Accepted: September 12, $2014 \quad$ Online Published: September 23, 2014

URL: http://dx.doi.org/10.5430/crim.v2n1p30

\section{Abstract}

Tuberculosis remains a very important issue of global health. The extrapulmonary tuberculosis forms (TBE) can be observed in less than $30 \%$ of all patients suffering from this disease. Pleural tuberculosis has a nonspecific presentation, which may delay the diagnosis. The polymerase chain reaction (PCR) applied for the identification of mycobacterial DNA facilitates a quick diagnosis in pleural tuberculosis. However, when the result is negative, and the patient is co-infected with other pathogens, the diagnosis may be delayed. We present a case of an immunocompetent patient with pleural tuberculosis and concomitant Flavimonas oryzihabitans bacteriemia, who was successfully treated with anti-tuberculosis treatment and antibiotic.

\section{Keywords}

Pleural effusion, Immunocompetent, Pseudomonas oryzihabitans

\section{Introduction}

Tuberculosis remains a very important issue of global health. The extra-pulmonary tuberculosis forms (TBE) can be observed in less than $30 \%$ of all patients suffering from this disease ${ }^{[1]}$. The stage of immunosuppression influences in the locations of the TBE: in immunocompetent patients with greater frequency is located in the pleura, the lymphatic and the genitourinary systems ${ }^{[2]}$, and in patients with HIV infection, lymphatic localization has been the most frequently found.

Pleural tuberculosis has a nonspecific presentation, which may delay the diagnosis. The polymerase chain reaction (PCR) applied for the identification of mycobacterial DNA facilitates a quick diagnosis in pleural tuberculosis ${ }^{[3]}$. However, when the result is negative, and the patient is co-infected with other pathogens, the diagnosis may be delayed. We present a case of an immunocompetent patient with pleural tuberculosis and concomitant Flavimonas oryzihabitans bacteriemia, who was successfully treated with anti-tuberculosis treatment and antibiotic.

\section{Case report}

A 20-year-old female, smoker of 1 pack of cigarettes per day for the last 5 years. She lives with his brother who was diagnosed 10 months ago of pulmonary tuberculosis and was correctly treated with clinical and microbiological remission. 
After the diagnosis of his brother, the patient underwent a tuberculin test, which was negative, and a chest x-ray that was informed as normal; in this setting primary chemoprophylaxis with isoniazid for 3 months was indicated but the patient refused to initiate the treatment. She experienced left pleuritic chest pain and profuse night sweats for one week, and decided to visit the Emergency department. Upon arrival her blood pressure was 110/80 $\mathrm{mmHg}$, heart rate was $80 / \mathrm{min}$, respiratory rate was $18 / \mathrm{min}$, and body temperature was $37.1^{\circ} \mathrm{C}$. A physical exam revealed decreased breathing sounds and vocal vibrations at the base of the left lung field. Laboratory findings were as follows: white cell count $5680 / \mu \mathrm{L}$, proportion of neutrophils $62 \%$, proportion of lymphocytes $28 \%$, platelet count, hemoglobin and renal function were normal, and C-reactive protein $7.3 \mathrm{mg} / \mathrm{dl}$. Chest radiography (see Figure 1) disclosed a left pleural effusion and diagnostic thoracentesis was performed. Pleural effusion samples were obtained and cell counting, biochemistry, $\mathrm{pH}$ evaluation, gram staining, acid-fast staining, M. Tuberculosis culture, TB PCR-Xpert MTB-RIF, and cytology were performed. The findings indicated lymphocyte predominance and revealed a turbid exudate (quotient lymphocytes/polymorphonuclear 2.9) with normal $\mathrm{pH}$; high ADA (60 U/l), bacterial culture, cytology, PCR-Xpert MTB-RIF and M. tuberculosis culture were negative. The patient exhibited high fever so blood cultures were performed and empirical antibiotic treatment with piperacillin-tazobactam and gentamicin was initiated. Days later, Flavimonas oryzihabitans was detected in the blood culture susceptible to ciprofloxacin, aminoglycosides, ceftazidime and piperacillin-tazobactam. The antibiotic treatment was modified to ciprofloxacin and 14 days were completed. The human immunodeficiency virus screen test was negative, and the CD4/CD8 ratio was 1.74 (normal). Because of the persistence of pleural effusion and intermittent fever, a pleural biopsy was performed and the samples were sent to the pathology and microbiology departments. Fibrosis was informed and the culture for Mycobacterium tuberculosis was found to be positive. Anti-tuberculosis treatment was initiated with Isoniazid, rifampin and pyrazinamide for 2 months, and later with isoniazid and rifampicin for 4 months with a favorable clinical and radiological outcome (see Figure 2).

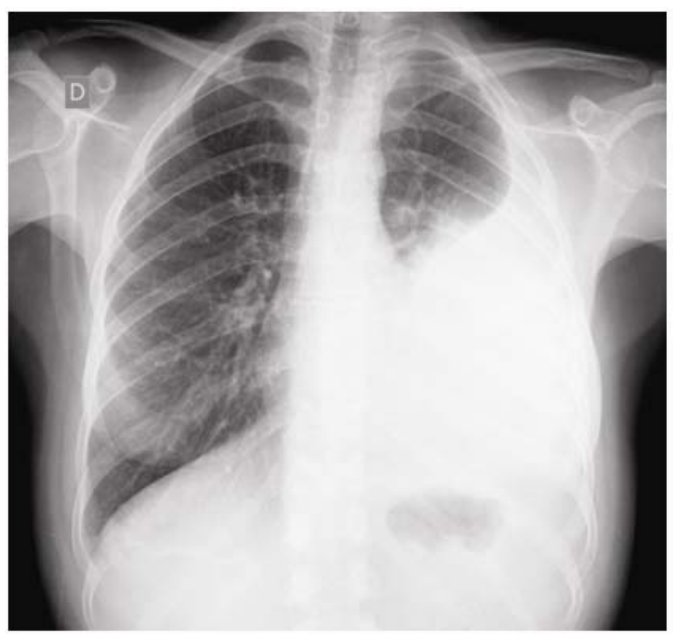

Figure 1. Left pleural effussion

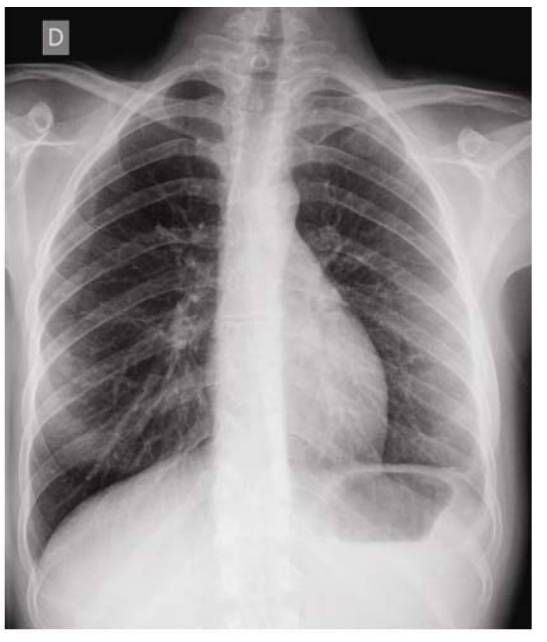

Figure 2. Minimal left pleural effussion

\section{Discussion}

We described a bacteremia caused by Flavimonas oryzihabitans in a patient with pleural tuberculosis. This co-infection was already described in a single occasion ${ }^{[4]}$, although in that case the immunity mediated by $\mathrm{T}$ cells was altered, this does not happened in our case in which the CD4/CD8 T lymphocytes relationship was normal. This is the second case described in the literature in which an association of pleural tuberculosis and bacteriemia by Flavimonas oryzihabitans is found; perhaps this association should be examined.

Pseudomonas oryzihabitans, previously known as Flavimonas oryzihabitans is a gram-negative bacillus, positive catalase, and negative oxidase included in the Ve-2 CDC (Centers for Disease control and Prevention). 
Initially this microorganism was isolated in samples of wounds, abscesses, tissues, body fluids and hospital equipment, without being considered pathogen until 1977 when the first case of infection by this microorganism was reported ${ }^{[5]}$. Numerous cases of infections have been collected in the literature, especially in patients with intracorporal devices, after aggressive maneuvers (surgery, dialysis, invasive explorations) ${ }^{[6-8]}$, in immunocompromised patients (hematological disorders, aids, renal failure, malignancy, corticotherapy, cirrhosis) ${ }^{[6-8]}$ and especially in hospital environment.

In our case, the epidemiological history of the patient, the persistence of fever and the pleural effusion, spite of the antibiotic treatment, forced us to make other studies in order to rule out the presence of pleural tuberculosis. This diagnosis must be considered in any patient with a pleural effusion with a non-eosinophilic lymphocyte exudate $(<10 \%)$ and with $<5 \%$ of mesothelial cells. The conventional diagnosis is performed through the identification of mycobacteria in pleural fluid by direct staining or culture, with yields rarely higher than 50\% (23\%-86\%), and in pleural biopsy tissue (39\%-71\%), although the findings of necrotic granulomas in the pleural biopsy is the most profitable test (51\%-87,8\%). The PCR applied for the identification of mycobacterial DNA is a rapid method for the diagnosis of pleural tuberculosis and could decrease the time required to identify the organism in clinical practice with a sensitivity of only $50 \%-70 \%{ }^{[9]}$. However, it has been suggested that in a pleural biopsy sample the sensitivity could increase to $90 \%^{[10]}$.

In our case, the PCR and baciloscopy were negative in the pleural effusion sample and pleural biopsy, causing a delay in the diagnosis and in starting the treatment. We obtained a definitive diagnosis through the culture of the mycobacteria.

\section{References}

[1] Torgersen J, Dorman SE, Baruch N, et al. Molecular epidemiology of pleural and other extrapulmonary tuberculosis: a Maryland state review. Clin Infect Dis. 2006; 42(10): 1375-1382. PMid:16619148 http://dx.doi.org/10.1086/503421

[2] Caminero JA, Fuentes ZM, Martin TY, et al. A 6-month regimen for EPTB with intermittent treatment in the continuation phase: a study of 679 cases. Study with 679 cases. Int J Tuberc Lung Dis. 2005; 9: 890-5. PMid:16104636

[3] Querol JM, Minguez J, García-Sánchez E, et al. Rapid diagnosis of pleural tuberculosis by polymerase chain reaction. Am J Respir Crit Care Med. 1995; 152(6): 1977-1981. PMid:8520765 http://dx.doi.org/10.1164/ajrccm.152.6.8520765

[4] Lin TY, Wu SW, Lin GM, et al. Hidden diagnosis of Tuberculous pleurisy masked by concomitant Pseudomonas oryzihabitans bacteremia. Respir Care. 2012; 57(2): 298-301. PMid:21762552

[5] Pied FD. Group Ve-2 (Chromobacterium typhiflavum) bacteremia. J Clin Microbiol. 1977; 6(4): 435-436.

[6] Rahav G, Simhon A, Mattan Y, et al. Infections with Chryseomonas luteola (CDC group Ve-1) and Flavimonas oryzihabitans (CDC group Ve-2). Medicine (Baltimore). 1995; 74: 83-8. http://dx.doi.org/10.1097/00005792-199503000-00003

[7] Decker CF, Simon GL, Keiser JF. Flavimonas oryzihabitans (Pseudomonas oryzihabitans; CDC group Ve-2) bacteremia in the inmunocompromised host. Arch Intern Med. 1991; 151(3): 603-4. PMid:2001143 http://dx.doi.org/10.1001/archinte.1991.00400030133026

[8] Lejbkowicz F, Belavsky L, Kudinsky R, et al. Bacteremia and sinusitis due to Flavimonas oryzihabitans infection. Scand J Infect Dis. 2003; 35(6-7): 411-4. PMid:12953957 http://dx.doi.org/10.1080/00365540310012208

[9] Nagesh BS, Sehgal S, Jindal SK, et al. Evaluation of polymerase chain reaction for detection of Mycobacterium tuberculosis in pleural fluid. Chest. 2001; 119(6): 1737-1741. PMid:11399699 http://dx.doi.org/10.1378/chest.119.6.1737

[10] Hasaneen NA, Zaki ME, Shalaby HM, et al. Polymerase chain reaction of pleural biopsy is a rapid and sensitive method for the diagnosis of tuberculous pleural effusion. Chest. 2003; 124(6): 2105-2111. PMid:14665487

http://dx.doi.org/10.1378/chest.124.6.2105 